University of Nebraska - Lincoln

DigitalCommons@University of Nebraska - Lincoln

U.S. Department of Veterans Affairs Staff

Publications

U.S. Department of Veterans Affairs

2001

\title{
Visual P3 findings in Mission Indian youth: relationship to family history of alcohol dependence and behavioral problems
}

\author{
Cindy L. Ehlers \\ University of California - San Diego, cindye@scripps.edu \\ Tamara L. Wall \\ Veterans Affairs San Diego Healthcare System, twall@ucsd.edu \\ Consuelo Garcia-Andrade \\ The Scripps Research Institute \\ Evelyn Phillips \\ The Scripps Research Institute
}

Follow this and additional works at: https://digitalcommons.unl.edu/veterans

Ehlers, Cindy L.; Wall, Tamara L.; Garcia-Andrade, Consuelo; and Phillips, Evelyn, "Visual P3 findings in Mission Indian youth: relationship to family history of alcohol dependence and behavioral problems" (2001). U.S. Department of Veterans Affairs Staff Publications. 49.

https://digitalcommons.unl.edu/veterans/49

This Article is brought to you for free and open access by the U.S. Department of Veterans Affairs at DigitalCommons@University of Nebraska - Lincoln. It has been accepted for inclusion in U.S. Department of Veterans Affairs Staff Publications by an authorized administrator of DigitalCommons@University of Nebraska - Lincoln. 


\title{
Visual P3 findings in Mission Indian youth: relationship to family history of alcohol dependence and behavioral problems
}

\author{
Cindy L. Ehlers ${ }^{\mathrm{a}, \mathrm{b}, *}$, Tamara L. Wall ${ }^{\mathrm{a}, \mathrm{b}, \mathrm{c}}$, Consuelo Garcia-Andrade ${ }^{\mathrm{a}}$, \\ Evelyn Phillips ${ }^{\mathrm{a}}$ \\ ${ }^{a}$ Department of Neuropharmacology, The Scripps Research Institute, CVN-14, 10550 North Torrey Pines Road, La Jolla, \\ CA 902037, USA \\ ${ }^{\mathrm{b}}$ Department of Psychiatry University of California at San Diego, La Jolla, CA, USA \\ ${ }^{\mathrm{c}}$ Veterans Affairs San Diego Healthcare System, San Diego, CA, USA
}

Received 28 December 2000; received in revised form 19 September 2001; accepted 20 September 2001

\begin{abstract}
Native Americans have some of the highest rates of alcohol abuse and dependence, yet risk factors for problem drinking remain relatively unknown. The amplitude of the P3 component of the event-related potential (ERP) has been suggested to be an index of 'vulnerability to alcoholism', especially when it is elicited by visual tasks in younger individuals. Visual P3 tasks, however, have not been previously investigated in Native American youth. One hundred and four Mission Indian youth between the ages of 7 and 13 years participated in the study. ERPs were collected using two visual target paradigms: a facial discrimination and an estimation of line orientation task. Analyses of covariance revealed that participants with a first degree family history of alcoholism had lower P3 component amplitudes in frontal leads to the facial discrimination task. Lower P3 amplitudes, in posterior areas, were found in the line discrimination task in children who scored above the 75th percentile in delinquent behaviors on the Achenbach Child Behavior Checklist. These findings are consistent with investigations in non-Indian populations demonstrating that the late positive component of the event related potential is sensitive to both familial history of alcohol dependence as well as personal history of externalizing behaviors. (c) 2001 Elsevier Science Ireland Ltd. All rights reserved.
\end{abstract}

Keywords: Native Americans; P300; Alcoholism; Event-related potential; Achenbach Child Behavior Checklist

\footnotetext{
* Corresponding author. Tel.: +1-858-784-7058; fax: +1-858-784-7409.

E-mail address: cindye@scripps.edu (C.L. Ehlers).
} 


\section{Introduction}

Although tribes differ with regard to the use of alcohol, epidemiological studies demonstrate that Native Americans as a whole have higher alcohol dependence rates as well as higher alcohol-related morbidity and mortality (see Andre, 1979; May, 1982; US Indian Health Service, 1982). Several investigators have commented on the paucity of research into the etiology of problem drinking and alcohol-related health problems in Native Americans, especially considering the magnitude of the problem (Brod, 1975; Young, 1991; Robin et al., 1998; Spicer, 1997, 1998).

Findings on the importance of genetics in the etiology of alcohol dependence have stimulated a number of investigators to search for factors that might mediate increased risk for the disorder. There is evidence to suggest that electrophysiological variables may represent 'markers' of vulnerability to alcohol dependence (see Begleiter and Porjesz, 1999; Ehlers et al., 1999; Enoch et al., 1995, 1999; Polich et al., 1994). One measure that has received considerable attention as a possible neurophysiological marker for alcoholism risk is the P3 component of the event-related potential (ERP). Many studies have demonstrated that the amplitude of the P3 (a positive-going potential that occurs approx. $250-500 \mathrm{~ms}$ following a 'target' stimulus) is reduced in individuals who have a family history of alcoholism but who have not yet developed the disorder (see Elmasian et al., 1982; Begleiter et al., 1984; O'Connor et al., 1986, 1987; Whipple et al., 1988; Hill et al., 1987, 1988, 1990, 1995, 1999; Porjesz and Begleiter, 1990, 1998; Berman et al., 1993a,b; Hill and Steinhauer, 1993; Steinhauer and Hill, 1993; Ramsey and Finn, 1997; Van der Stelt et al., 1998). Other studies are less convincing or do not support this hypothesis (see Baribeau et al., 1987; Bauer, 1997; Polich and Bloom, 1987, 1988; Hill et al., 1988; Bauer, 1994a,b; Holguin et al., 1998; Bauer and Hesselbrock, 1999a,b). However, a meta-analysis concluded that the P3 'may be useful as an index for predicting alcoholism vulnerability,' particularly in younger children (Polich et al., 1994). In that study, as well as some others (see Hill et al., 1999), the strongest evidence for decrements in P3 amplitude in relationship to family history of alcoholism were found when ERPs were elicited by relatively difficult visual tasks, and in relatively young males.

It has been suggested that differences in ERP findings between studies may relate to heterogeneity in samples based on the presence of other psychiatric disorders (see Hill et al., 1999). Several recent publications have shed light on this area of controversy. Bauer, Hesselbrock, and colleagues have made a cogent case for the hypothesis that $\mathrm{P} 3$ reduction in individuals with a family history of alcoholism is primarily related to conduct disorder and its subtypes. In adults diagnosed with antisocial personality disorder (ASPD) (Bauer, 1994a,b, 1997; O'Connor et al., 1994; Costa et al., 2000) or in youth with elevated numbers of conduct disorder behaviors (Bauer and Hesselbrock, 1999a,b), decrements in P3 amplitude were observed. In fact they have stated that: 'the P300 effects of a family history of alcohol/drug dependence appear to be negligible when its overlap with conduct disorder/ASPD is considered' (Bauer and Hesselbrock 1999a,b).

The present investigation was designed to explore the relationships between visual P3 amplitude and potential vulnerability factors associated with risk for alcohol dependence in Mission Indian youth. This population is important because of their substantially elevated risk for alcoholism (see Gilder et al., 1999). The present report is part of a larger study exploring risk factors for alcoholism among Native American Mission Indians (Ehlers et al., 1998, 1999, 2001a,b,c; GarciaAndrade et al., 1996, 1997; Wall et al., 1996, 1997, 2000). This study represents an extension of previous findings to the evaluation of Mission Indian children and adolescents between the ages of 7 and 13 who have had no alcohol or drug exposure. Based on the meta-analysis of Polich et al. (1994), the present study used two visual discrimination tasks: a facial discrimination task (Gur et al., 1992; Erwin et al., 1992; Heimberg et al., 1992) that was adapted for use in an ERP paradigm (Orozco and Ehlers, 1998) and an estimation of line task described by Porjesz and Begleiter (1990). The specific aims of this study were to: (a) evaluate whether visual P3 amplitude 
was related to family history of alcoholism; and (b) determine if a personal history of delinquent/aggressive behaviors was associated with reduced P3 amplitude. Additionally, in order to compare data from this study to those for other ethnic groups, data on P3 latency are also provided.

\section{Methods}

\subsection{Participants}

A group of Native Americans known collectively as Mission Indians were recruited to participate in the study. Individual participants were recruited from six geographically contiguous Indian reservations in southern California. Parents or guardians of children between the ages of 7 and 13 years responded to fliers posted at the Indian Health Clinic, tribal halls, local schools, and local businesses and were also recruited by word-of-mouth. The inclusion criteria were at least one child or adolescent between 7 and 13 years of age who was of at least $1 / 16$ th Native American heritage as determined by their federal Indian blood quantum, as well as information regarding the youth's family history of alcoholism. Individual informed consent was obtained from one biological parent or legal guardian and from each youth before participation in the study. Parents and/or guardians completed a screening questionnaire that gathered information on demography, personal medical and psychiatric history, and family history of alcohol and other substance dependence. The adult participant also completed the Achenbach Child Behavior Checklist (CBCL) (Achenbach and Edelbrock, 1983). The CBCL has been one of the most widely used measures of child and adolescent functioning. Extensive data regarding the reliability and validity of this instrument are available. Minor participants were excluded from further study if they were taking any prescribed medication or had any major medical condition (i.e. organ system disease, neurological disorder, head injury, endocrine disorder).

A youth was classified as family history positive
(FHP) if he or she had a biological parent who met lifetime DSM-III-R criteria for alcohol dependence. Family history status was additionally verified in some parents who were part of the larger study by direct psychiatric interview using the Family History Assessment module developed by the collaborative study on the genetics of alcoholism (COGA), and in others by query of a tribal elder and/or other family members. Family history negative (FHN) youth lacked a history of alcohol dependence in all first degree relatives.

\subsection{ERP collection and analyses}

Seven channels of ERP data (FZ, CZ, PZ, F3, F4, F7, and F8, referenced to linked ear lobes with a forehead ground, international 10-20 system) were obtained using gold-plated electrodes with impedance held below $5 \mathrm{~K} \Omega$. Frontal electrodes were emphasized in the montage as previous data had suggested that P3 decrements in frontal areas distinguished subjects with a family history of alcoholism (see Bauer, 1997). An electrode placed left lateral infraorbitally and referenced to the left earlobe was used to monitor both horizontal and vertical eye movements. ERP recording signals were amplified at a sensitivity of $7 \mathrm{mV} / \mathrm{mm}$ (time constant $0.3 \mathrm{~s}, 35 \mathrm{~Hz}$ low pass) using a Nihon Kohden EEG machine and were transferred on-line to a Macintosh computer for digitization. Visual stimuli were presented on a video screen and ERPs were elicited using two visual paradigms. For the first paradigm stimuli were happy, neutral, and sad faces presented on a computer screen for $1000 \mathrm{~ms}$ with an intertrial interval of 1000-1500 ms. The pre-stimulus interval was $150 \mathrm{~ms}$. Participants were instructed to depress a counter whenever a happy or sad face was displayed ( $15 \%$ of the trials each) and not to respond to neutral faces ( $70 \%$ of the trials). There were 36 total faces (12 each of happy, neutral, and sad) presented in random order for a total of 216 trials. For the second paradigm a modification of the estimation of line task described by Porjesz and Begleiter (1990) was used. In this task, participants focused on a dot in the center of a computer screen, and a series of stimuli were presented. The stimuli consisted of vertical lines) 
(non-targets, $n=150$ ), horizontal lines (easy to discriminate targets, $n=25$ ), and lines $3^{\circ}$ from vertical (hard to discriminate targets, $n=25$ ) for a total of 200 trials. The stimuli were presented for $30 \mathrm{~ms}$ with a random interstimulus interval varying between 2 and $3 \mathrm{~s}$ apart. Similar paradigms have been used in our laboratory (see Wall and Ehlers, 1995; Ehlers et al., 1996, 1999; Orozco and Ehlers, 1998; Orozco et al., 1999).

The ERP trials were digitized at a rate of 256 Hz. Individual trials containing excessive eye movement artifact as well as trials where the EEG exceeded $\pm 250 \mathrm{mV}$ ( $<5 \%$ of the trials) were eliminated before averaging. The occurrence of eye movements was noted on individual trials and eliminated prior to averaging. For target stimuli, only trials with correct identification were included in the averaging. The percent correctly identified targets for the line task was 84 and $81 \%$ for the facial discrimination task. The P3 was defined as the occurrence of a peak after the N1-P2-N2 complex within $250-600 \mathrm{~ms}$ after stimulus presentation. The amplitude was determined as baseline to that peak (microvolts), and the latency was determined as the time from the onset of the stimulus to the occurrence of the peak (milliseconds). The baseline was determined by averaging the $100 \mathrm{~ms}$ of prestimulus activity obtained for each trial. The routine is user-driven and each peak detection must be verified by the user. All peaks were quantified by one investigator (E.P., R EEG Tech), and verified by a second investigator (C.L.E.), both of whom were blind to participant characteristics.

\subsection{Data analyses}

Data analyses focused on two specific aims based on previous ERP research in populations at varying degrees of risk for the development of alcoholism (see Bauer and Hesselbrock, 1999a,b), as well as ERP studies of adults from this Mission Indian population (Ehlers et al., 1998). To analyze the P3 amplitude data, a principal components analysis (PCA) was performed over the seven electrode locations for P3 amplitude to the two target stimuli (easy and difficult) in the line task and to the three faces (happy, sad, neutral) in the facial recognition task, to determine their topography. For both tasks and for each of the stimuli, varimax rotation yielded two components (eigenvalues $>1.0$, range 1.1-4.8). The electrode sites loading on the first factor were the frontal leads (FZ, F3, F4, F7, F8) (loadings ranged from 0.6 to 0.9 ). The electrode sites loading on the second factor were the two more posterior leads (CZ, PZ) (loadings ranged from 0.8 to 0.9 ).

The two orthogonal factors each explained between 26 and $53 \%$ of the variance, and together explained between 75 and $80 \%$ of the variance for the two ERP tasks (sad face 78\%, happy face $76 \%$; neutral face 74\%) (horizontal line $80 \%$, off-vertical line $76 \%$ ). P3 amplitude was averaged across the electrode sites within each of the two identified components $1=(\mathrm{FZ}, \mathrm{F} 3, \mathrm{~F} 4, \mathrm{~F} 7, \mathrm{~F} 8)$, $2=(\mathrm{CZ}, \mathrm{PZ})$ generating a mean for each of the two regions. These regionally averaged scores were generated for each stimulus condition for the two ERP paradigms (happy, sad, neutral) (horizontal line, off-vertical line) generating a mean amplitude for each of the two component regions, for each stimulus category for each individual.

The first aim was to describe the relationship between P3 amplitude and a participant's parental history of alcohol dependence. To investigate this aim, the regionally averaged P3 amplitudes generated by the two ERP tasks, for each stimulus condition described above were used as dependent variables. Using ANCOVA, FH was treated as a between-subjects variable and age and gender were covariates. This same analyses was used to exclude any association of P3 latency on these variables. The second aim was to explore the relationship between P3 amplitude and problem behaviors associated with conduct disorders as measured by the Achenbach Child Behavior Checklist (CBCL) scales for Aggression and Delinquency. For these analyses, P3 amplitude for the two components identified in the PCA (frontal leads, centro-parietal leads) generated to the stimuli obtained from the estimation of line task (horizontal line, off-vertical line) were evaluated; data from the facial discrimination task were not evaluated due to the smaller number of subjects participating. Participants who scored 
above the 75th percentile based on age and gender on the Aggression and/or Delinquency scales from the CBCL compared to those whose scores were below the 75 th percentile. Chi-square or Fisher exact test (depending on sample size) was used to evaluate potential differences in demographic variables between groups (FHP vs. FHN, CBCL score groups). Statistical significance was set at the 0.05 probability level.

\section{Results}

\subsection{Descriptive data}

The children and adolescents who participated in the study had a mean age of 9.9 years (S.D. $=$ \pm 1.7 years), with approximately equal numbers of boys and girls in the study. Due to a difference in software development time 104 youths participated in the discrimination of line task, whereas 64 individuals participated in both tasks. Demographic data including age, gender, and percent Native American heritage (NAH) are presented as a function of parental history of alcoholism in Table 1. There were no significant differences in these demographic variables as a function of family history of alcoholism.

Mean P3 latency for all leads for the easy target (horizontal line) in the line task was $470 \pm$ $49 \mathrm{~ms}$. This value is similar to what has been reported previously for an easy visual target task for children of non-Indian heritage in this age range $(466 \pm 55 \mathrm{~ms})$ by Sangal et al. (1998). No significant associations were detected for P3 latency and FH or NAH. Age and gender were related to P3 amplitude, but only for the horizontal line in the line discrimination task. Older boys had larger P3 amplitudes than younger boys or girls of both age ranges [younger girls: mean $=6.4$ \pm 0.9 ; younger boys: mean $=6.5 \pm 0.9$; older girls: mean $=4.5 \pm 1.3$; older boys: mean $=10.4 \pm 1.4$ (ANOVA, gender: $F=6.7, \quad P<0.01$; age $\times$ gender: $F=6.4, P<0.01)]$. However, post-hoc analyses revealed that this effect was mediated by one older male subject whose value was more than 2 S.D.s larger than the mean. Removal of that subject from the analyses led to non-significant findings for age and gender for all amplitude measures. Subsequent analyses were conducted covarying for age and gender. There were no significant differences in P3 amplitude based on whether a participant was less than $50 \% \mathrm{NAH}$ or greater than or equal to $50 \%$ NAH. ERP responses to both paradigms are shown in Fig. 1 and appear to resemble those reported for children of other ethnicities (see Sangal et al., 1998; Sangal and Sangal, 1996).

\subsection{Associations of P3 amplitude with parental alcoholism}

Consistent with other studies of Native American youth, approximately three-quarters of the

Table 1

Demographics for Mission Indian youth

\begin{tabular}{|c|c|c|c|c|}
\hline \multirow[t]{2}{*}{ Age group } & \multicolumn{2}{|c|}{ Facial discrimination task } & \multicolumn{2}{|c|}{ Discrimination of line task } \\
\hline & FHP & FHN & FHP & FHN \\
\hline \multicolumn{5}{|l|}{ Age group } \\
\hline $7-11$ years & 44 & 11 & 56 & 17 \\
\hline $12-13$ years & 4 & 5 & 21 & 10 \\
\hline \multicolumn{5}{|l|}{ Gender } \\
\hline Female & 25 & 9 & 39 & 15 \\
\hline Male & 23 & 7 & 38 & 12 \\
\hline \multicolumn{5}{|c|}{ Native American heritage } \\
\hline$<50 \%$ & 42 & 10 & 61 & 19 \\
\hline$\geq 50 \%$ & 5 & 3 & 15 & 6 \\
\hline Unknown & 1 & 3 & 1 & 2 \\
\hline
\end{tabular}




\section{VISUAL ERPS IN MISSION INDIAN YOUTH}

\section{Facial Discrimination}
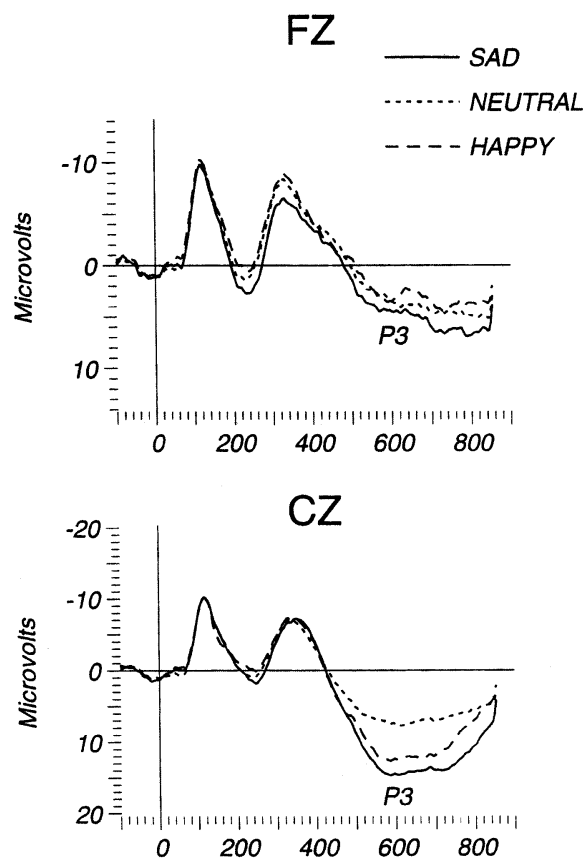

$\mathrm{PZ}$

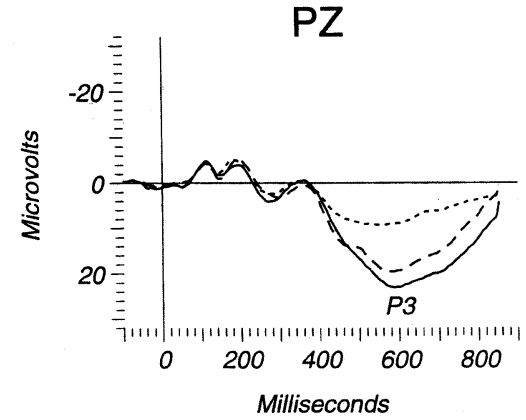

Discrimination of Lines
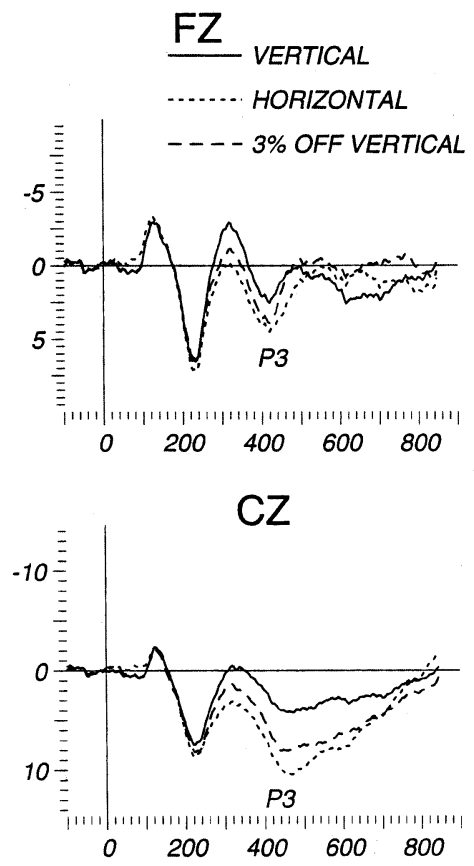

$\mathrm{PZ}$

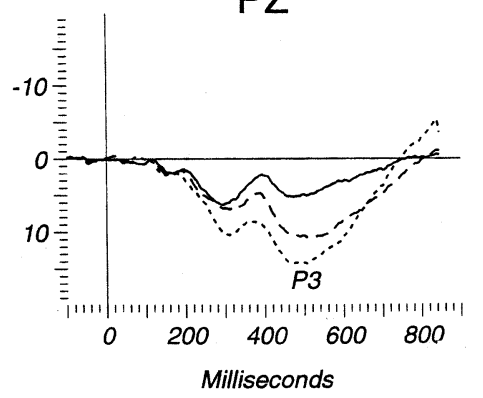

Fig. 1. Grand averages of ERPs elicited by two visual discrimination tasks in Mission Indian youth. In the left column, averages are presented for 64 participants, for the facial discrimination task, and in the right column the 104 participants for the line discrimination task. Averages are presented for frontal (FZ), central (CZ), and parietal (PZ) leads for each task. N1 and P2, and P3 components are visible in response to vertical lines (solid lines), horizontal lines (dotted lines), and off vertical lines (dashed lines) on the right and to neutral faces (solid lines), sad faces (dotted lines), and happy faces (dashed lines) on the left.

children and adolescents participating in this study had at least one parent with a lifetime diagnosis of alcohol dependence. Of the 77 children who were family history positive, 75 also had second degree relatives with a lifetime alcohol depen- dence diagnosis. In addition, 10 participants had a mother who met criteria for alcohol dependence during that child's pregnancy. An ANCOVA that co-varied for age and gender revealed differences in P3 amplitude on the basis of parental history 


\section{ERPS to NEUTRAL FACIAL EXPRESSIONS}

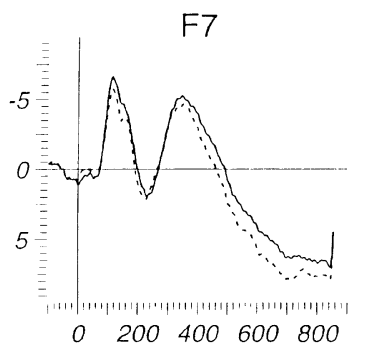

F8

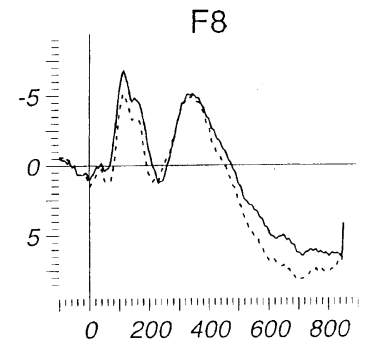

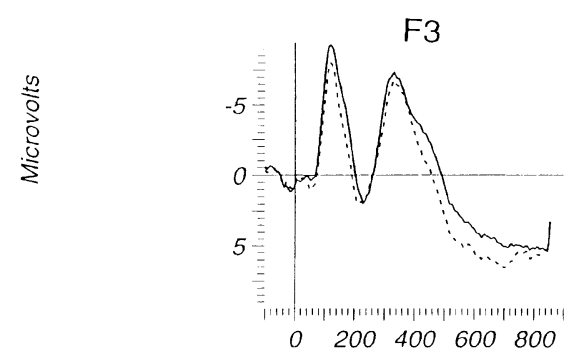
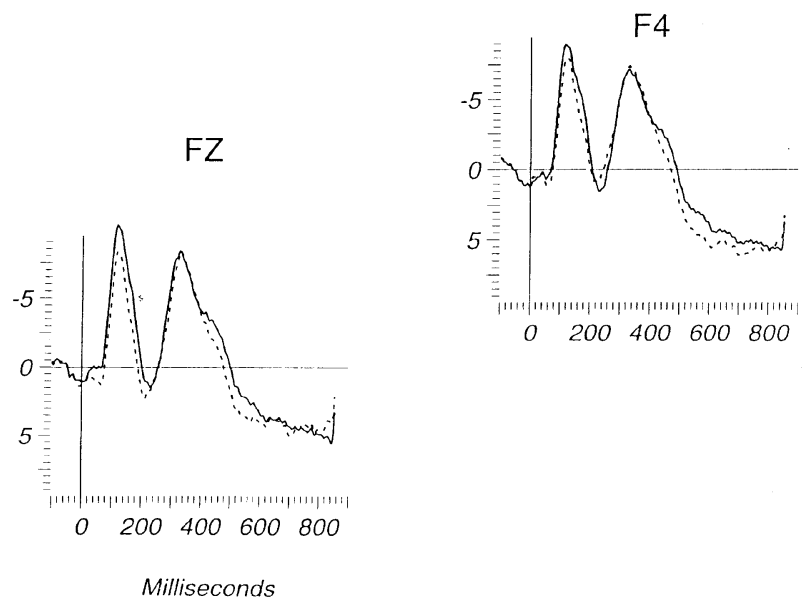

Fig. 2. Grand averages of ERPs elicited by neutral faces for the facial discrimination task in Mission Indian youth. Averages are presented for frontal (FZ, F3, F4, F7 and F8) leads. Data are presented for youths who were family history positive (FHP, solid line) and those who were family history negative (FHN, dotted line) for alcohol dependence. Those participants with at least one alcoholic parent were found to have smaller P3 amplitudes in the frontal leads in response to the neutral faces $(F=4.25$; d.f. $=1,60 ; P<0.04)$.

of alcoholism in the facial discrimination task. Those participants with at least one alcoholic parent were found to have smaller P3 amplitudes in the frontal leads in response to the neutral faces $(\mathrm{FHP}$ mean $=4.67 \pm 0.4 ; \mathrm{FHN}$ mean $=6.5$ $\pm 0.8, F=4.25$; d.f. $=1,60 ; P<0.04)$. This effect is illustrated in Fig. 2. To determine whether having a mother who was alcoholic during pregnancy might influence P3 amplitude, data from the 10 children who participated in the estimation of line task and the five children who participated in the facial recognition task, who had alcoholic mothers, were compared to the remaining chil- dren and no significant differences were revealed. Additionally, analyses were conducted removing the children with alcoholic mothers and significances were not altered.

\subsection{Association of P3 amplitude with the CBCL}

Problem behaviors as assessed by responses on the Aggression and Delinquency scales on the CBCL were also investigated as a source of variation in P3 amplitude in this population of Mission Indian youth. P3 amplitudes generated to both tasks were compared between participants who 
Table 2

CBCL scores and P3 amplitude ( $\mathrm{mV}$ mean \pm S.D.)

\begin{tabular}{|c|c|c|}
\hline & $\begin{array}{l}<75 \text { percentile } \\
(n=80)\end{array}$ & $\begin{array}{l}\geq 75 \text { percentile } \\
(n=21)\end{array}$ \\
\hline \multicolumn{3}{|l|}{ Aggression } \\
\hline \multicolumn{3}{|l|}{ Easy target } \\
\hline $\begin{array}{l}\text { Frontal } \\
\qquad F=0.1, P<0.9\end{array}$ & $6.6 \pm 5.34$ & $6.6 \pm 5.4$ \\
\hline $\begin{array}{l}\text { Centro-parietal } \\
\qquad F=3.1, P<0.8\end{array}$ & $16.4 \pm 7.12$ & $13.3 \pm 6.75$ \\
\hline \multicolumn{3}{|l|}{ Hard target } \\
\hline $\begin{array}{l}\text { Frontal } \\
\qquad F=0.6, P<0.4\end{array}$ & $6.0 \pm 4.45$ & $5.3 \pm 3.6$ \\
\hline $\begin{array}{l}\text { Centro-parietal } \\
\qquad F=3.1, P<0.8\end{array}$ & $12.5 \pm 7.12$ & $9.2 \pm 7.2$ \\
\hline \multicolumn{3}{|l|}{ Easy target } \\
\hline $\begin{array}{l}\text { Frontal } \\
\qquad F=0.9, P<0.8\end{array}$ & $6.7 \pm 5.8$ & $6.4 \pm 5.4$ \\
\hline $\begin{array}{l}\text { Centro-parietal } \\
\qquad F=4.6, P<0.03\end{array}$ & $16.7 \pm 6.64$ & $13.4 \pm 7.0$ \\
\hline \multicolumn{3}{|l|}{ Hard target } \\
\hline $\begin{array}{l}\text { Frontal } \\
\qquad F=5.1, P<0.02\end{array}$ & $6.5 \pm 4.15$ & $4.6 \pm 3.8$ \\
\hline $\begin{array}{l}\text { Centro-parietal } \\
\qquad F=7.1, P<0.009\end{array}$ & $13.1 \pm 7.47$ & $8.7 \pm 7.0$ \\
\hline
\end{tabular}

scored over the 75th percentile on the Aggression and Delinquency scales of the CBCL as compared to the remainder. There were no significant differences on demographic variables (age, $\mathrm{FH}$, $\mathrm{NAH}$, gender) between the participants who were less than vs. those greater than or equal to the 75 th percentile. Table 2 presents the findings of the analyses. Decreases in P3 amplitude, to the line estimation task, were found in those participants with delinquent behaviors that exceeded the 75th percentile. A non-significant trend for decreased P3 amplitudes was also found in those individuals that exceeded the 75 th percentile on aggressive behaviors on the line discrimination task.

\section{Discussion}

This study assessed the amplitude and latency of the P3 component of the ERP using two visual discrimination tasks in Native American Mission Indian youth. The study was designed to explore determinants of P3 amplitude in this population in relation to parental history of alcoholism and the presence of problem behaviors.

P3 amplitude is perhaps the most studied electrophysiological 'marker' of potential vulnerability to alcohol dependence. Many, but not all, studies have supported the notion that the amplitude of the P3 is reduced in FHP subjects (see Elmasian et al., 1982; Begleiter et al., 1984; O'Connor et al., 1986, 1987; Whipple et al., 1988; Hill et al., 1988, 1990; Begleiter and Porjesz, 1990; Porjesz and Begleiter, 1990; Berman et al., 1993a,b; Hill and Steinhauer, 1993; Steinhauer and Hill, 1993; Ramachandran et al., 1996). A meta-analysis of P3 amplitudes from 30 separate studies found that smaller P3 amplitudes were obtained from males with family histories of alcoholism compared to controls (Polich et al., 1994). However, a moderator analysis also indicated the ERP paradigms that used difficult visual tasks in younger participants, particularly in males, yielded the most reliable effects.

In the present study two visual tasks were employed. One required recognition of different facial expressions and the second a discrimination between lines of different orientations. These tasks elicited a late positive component that occurred between 400 and $600 \mathrm{~ms}$ after presentation of the stimuli. Most ERP studies using facial stimuli have reported that the amplitudes of the late positive components elicited by these paradigms are larger in response to more 'emotional' facial expressions compared with neutral expressions (Roschmann and Wittling, 1992; Laurian et al., 1991; Johnston et al., 1986; Vanderploeg et al., 1987; Orozco and Ehlers, 1998). Previous results from our laboratory using this facial recognition task demonstrated that neutral and sad faces were more difficult to discriminate than happy ones (Orozco and Ehlers, 1998). A significant relationship between parental history of alcoholism and the amplitude of the P3 late positive component elicited to the neutral faces was found in the present study. Male and female subjects with at least one alcoholic parent had lower P300 amplitudes than those without a family 
history of alcoholism. Because the neutral faces may be more difficult to discriminate, these findings are consistent with the meta-analytic conclusions of Polich et al. (1994) where difficult visual tasks were found to generate the most reliable discrimination of participants with and without a family history of alcoholism. Additionally, the present study suggests that the use of visual stimuli with more 'emotional' content, as compared to visual tasks with no emotional content, such as the line discrimination task or auditory paradigms (see Ehlers et al., 1998, 2001c), may be particularly discriminative of parental history of alcoholism in Mission Indians.

A previous study that used the same line discrimination task as in the present study found that young men with a family history of alcoholism had significantly lower P3's than comparable young men without such a history (Porjesz and Begleiter, 1990). This task did not discriminate on the basis of parental history of alcohol dependence in Mission Indians, perhaps because it was not found as difficult, as assessed by error rates, as the facial discrimination task. However, P3 amplitudes elicited by this task were associated with behavioral differences in the participants as assessed by the Aggression and Delinquency scales of the CBCL. Participants with scores above the 75th percentile on the Delinquency scale were found to have decrements in P3 amplitude when compared to those individuals with scores below that percentile. The findings were strongest in response to the difficult target compared with the easy target and were most prominent in the centro-parietal leads. These findings are consistent with a series of studies conducted by Bauer and Hesselbrock (1999a,b) in non-Indian populations. Their studies utilized visual tasks with non-emotional stimuli requiring either word recognition or object orientation, to evaluate a group of over 200 youths between 15 and 20 years of age. In those studies familial substance dependence was not associated with P3 amplitude reduction, but was found to be smaller in those participants with a greater number of conduct disorder problems prior to age 15 . Additionally, reduced P3 amplitude was related to the severity of the 'type' of conduct disorder symptom reported. The 'rules violation' subtype related to P3 decrements, but the 'aggression', 'deceitfulness' and 'theft' subtypes did not. While this kind of detailed analysis could not be conducted in the present study, it is of interest that P3 decrements were only significant in Mission Indian youth with delinquent behaviors and did not reach significance in those with aggressive behaviors.

Thus, Mission Indian children appear to respond to visual tasks that generate P3 components of the ERP in a similar manner to what has been reported in the literature for children of other ethnicities. These findings are consistent with several investigations in non-Indian populations which suggest that the late positive component of the ERP is sensitive to both familial history of alcohol dependence as well as personal history of conduct disorder-related behaviors, depending on the task used to generate the component.

\section{Acknowledgements}

The authors thank Susan Lopez and Philip Lau for help in data analyses and manuscript preparation. The software was written by Dr James Havstad. The research reported was supported by NIAAA RO1 AA10201, The Office of Minority Health, KO5 AA00223, KO2 AA00269, and M01RR00833.

\section{References}

Achenbach, T.M., Edelbrock, C., 1983. Manual for the Child Behavior Checklist and Revised Child Behavior Profile. Queen City Printers, Cincinnati.

Andre, J.M., 1979. The Epidemiology of Alcoholism among American Indians and Alaska Natives. U.S. Indian Health Services. U.S. Government Printing Office, Albuquerque, NM.

Baribeau, J.C., Ethier, M., Braun, C., 1987. Neurophysiological assessment of selective attention in males at risk for alcoholism. In: Johnson, R., Rohrbaugh, J., Parasuraman, R. (Eds.), Current Trends in Event Related Potential Research, EEG Supplement \#40. Elsevier, Amsterdam, pp. 651-656.

Bauer, L.O., 1994a. Electroencephalographic and autonomic predictors of relapse in alcohol-dependent patients. Alcoholism: Clinical and Experimental Research 18, 755-760. 
Bauer, L.O., 1994b. Frontal P300 decrements in antisocial personality disorder. Alcoholism: Clinical and Experimental Research 18, 1300-1305.

Bauer, L.O., 1997. Frontal P300 decrements, childhood conduct disorder, family history, and the prediction of relapse among abstinent cocaine abusers. Drug and Alcohol Dependence 44, 1-10.

Bauer, L.O., Hesselbrock, V.M., 1999a. P300 decrements in teenagers with conduct problems: implications for substance abuse risk and brain development. Biological Psychiatry 46, 264-272.

Bauer, L.O., Hesselbrock, V.M., 1999b. Subtypes of family history and conduct disorder: effects of P300 during the Stroop Test. Neuropsychopharmacology 21, 51-62.

Begleiter, H., Porjesz, B., 1990. Event-related potentials in populations at risk for alcoholism. Electroencephalography and Clinical Neurophysiology Supplement 41, 177-182.

Begleiter, H, Porjesz, B, 1999. What is inherited in the predisposition toward alcoholism? A proposed model. Alcoholism: Clinical and Experimental Research 23, 1125-1135.

Begleiter, H., Porjesz, B., Bihari, B., Kissin, B., 1984. Event-related brain potentials in boys at risk for alcoholism. Science 225, 1493-1496.

Berman, S.M., Martinez, R.A., Noble, E.P., 1993a. Familial alcoholism and ERPs: differences in probability sensitivity? Alcohol and Alcoholism 28, 695-707.

Berman, S.M., Whipple, S.C., Fitch, R.J., Noble, E.P., 1993 b. P3 in young boys as a predictor of adolescent substance abuse. Alcohol 10, 69-76.

Brod, T.M., 1975. Alcoholism as a mental health problem of Native Americans. Archives of General Psychiatry 32, 1385-1391.

Costa, L., Bauer, L., Kuperman, S., Porjesz, B., O'Connor, S., Hesselbrock, V., Rohrbaugh, J., Begleiter, H., 2000. Frontal P300 decrements, alcohol dependence, and antisocial personality disorder. Biological Psychiatry 47, 1064-1071.

Ehlers, C.L., Phillips, E., Parry, B.S., 1996. Electrophysiological findings during the menstrual cycle in women with and without late luteal phase dysphoric disorder: Relationship to risk for alcoholism. Biological Psychiatry 39, 720-732.

Ehlers, C.L., Garcia-Andrade, C., Wall, T.L., Cloutier, D., Phillips, E., 1998. Determinants of P3 amplitude and response to alcohol in Native American Mission Indians. Neuropsychopharmacology 18, 282-292.

Ehlers, C.L., Garcia-Andrade, C., Wall, T.L., Cloutier, D., Phillips, E., 1999. Electroencephalographic responses to alcohol challenge in Native American Mission Indians. Biological Psychiatry 45, 776-787.

Ehlers, C.L., Wall, T.L., Garcia-Andrade, C., Phillips, E., 2001a. Effects of age and parental history of alcoholism on EEG findings in Mission American children and adolescents. Alcoholism: Clinical and Experimental Research 25 (5), 672-679.

Ehlers, C.L., Wall, T.L., Garcia-Andrade, C., Phillips, E., 2001b. EEG asymmetry and risk for alcoholism in Mission Indian children. Biological Psychiatry 50 (2), 129-136.

Ehlers, C.L., Wall, T.L., Garcia-Andrade, C., Phillips, E., 2001c. Auditory ERP findings in Mission Indian youth. Journal of Studies on Alcohol (in press).

Elmasian, R., Neville, H., Woods, D., Schuckit, M., Bloom, F.E., 1982. Event-related brain potentials are different in individuals at high and low risk for developing alcoholism. Proceedings of the National Academy of Sciences USA 79, 7900-7903.

Enoch, M.A., Rohrbaugh, J.W., Davis, E.Z., Harris, C.R., Ellingson, R.J., Andreason, P., Moore, V., Varner, J.L., Brown, G.L., Eckardt, M.J., Goldman, D., 1995. Relationship of genetically transmitted alpha EEG traits to anxiety disorders and alcoholism. American Journal of Medical Genetics 60, 400-408.

Enoch, M.A., White, K., Harris, C., Robin, R., Ross, J., Rohrbaugh, J., Goldman, D., 1999. Association of low voltage alpha EEG with a subtype of alcohol use disorders. Alcoholism: Clinical and Experimental Research 23, 1312-1319.

Erwin, R.J., Gur, R.C., Gur, R.E., Skolnick, B., MawhinneyHee, M., Smailis, J., 1992. Facial emotion discrimination: I. Task construction and behavioral findings in normal subjects. Psychiatry Research 42, 231-240.

Garcia-Andrade, C., Wall, T.L., Ehlers, C.L., 1996. Alcohol expectancies in a native American population. Alcoholism: Clinical and Experimental Research 20, 1438-1442.

Garcia-Andrade, C., Wall, T.L., Ehlers, C.L., 1997. The firewater myth and response to alcohol in Mission Indians. American Journal of Psychiatry 154, 983-988.

Gilder, D.A., Wong, V., Lau, P., Wall, T.L., Garcia-Andrade, C., Vallone, M., Ehlers, C.L., 1999. Substance use and psychiatric disorders in Mission Indian adults [Abstract]. Alcoholism: Clinical and Experimental Research Supplement 23, 130A.

Gur, R.C., Erwin, R.J., Gur, R.E., Zwil, A.S., Heimberg, C., Kraemer, H.C., 1992. Facial emotion discrimination: II. Behavioral findings in depression. Psychiatry Research 42, 241-251.

Heimberg, C., Gur, R.E., Erwin, R.J., Shtasel, D.L., Gur, R.C., 1992. Facial discrimination emotion: III. Behavioral findings in schizophrenia. Psychiatry Research 42, 253-265.

Hill, S.Y., Steinhauer, S., 1993. Assessment of prepubertal and post-pubertal boys and girls at risk for developing alcoholism with P3 from a visual discrimination task. Journal of Studies on Alcohol 54, 350-358.

Hill, S.Y., Steinhauer, S.R., Zubin, J., 1987. Biological markers for alcoholism: a vulnerability model conceptualization. In: Rivers, P.C. (Ed.), Alcohol and Addictive Behaviors. Nebraska Symposium on Motivation, 1986. University of Nebraska Press, Lincoln, NE and London, pp. 207-256.

Hill, S.Y., Steinhauer, S., Zubin, J., Baughman, T., 1988. Event-related potentials as markers for alcoholism risk in high density families. Alcoholism: Clinical and Experimental Research 12, 545-554. 
Hill, S.Y., Steinhauer, S., Park, J., Zubin, J., 1990. Event-related potentials characteristics in children of alcoholics from high density families. Alcoholism: Clinical and Experimental Research 14, 6-17.

Hill, S.Y., Muka, D., Steinhauer, S., Locke, J., 1995. P300 amplitude decrements in children from families of alcoholic female probands. Biological Psychiatry 38, 622-632.

Hill, S.Y., Shen, S., Locke, J., Steinhauer, S.R., Konicky, C., Lowers, L., Connolly, J., 1999. Developmental delay in P300 production in children at high risk for developing alcohol-related disorders. Biological Psychiatry 46, 970-998.

Holguin, S., Corral, M., Cadaveira, F., 1998. Visual and auditory event-related potentials in young children of alcoholics from high- and low-density families. Alcoholism: Clinical and Experimental Research 22, 87-96.

Johnston, V.S., Miller, D.R., Burleson, M.H., 1986. Multiple P3s to emotional stimuli and their theoretical significance. Psychophysiology 23, 684-694.

Laurian, S., Bader, M., Lanares, J., Oros, L., 1991. Topography of event-related potentials elicited by visual emotional stimuli. International Journal of Psychophysiology 10, 231-238.

May, P.A., 1982. Substance abuse and American Indians: prevalence and susceptibility. International Journal of Addiction 17, 1185-1209.

O'Connor, S., Hesselbrock, V., Tasman, T., 1986. Correlates of increased risk for alcoholism in young men. Progess in Neuropsychopharmacology \& Biological Psychiatry 10, 211-218.

O’Connor, S., Hesselbrock, V., Tasman, T., DePalma, N., 1987. P3 amplitudes in two distinct tasks are decreased in young men with a history of paternal alcoholism. Alcohol 4, 323-330.

O'Connor, S., Tasman, A., Bauer, L.O., Hesselbrock, V.M., 1994. Reduced P3 amplitudes of ERPs are associated with both a family history of alcoholism and antisocial personality disorder. Progess in Neuropsychopharmacology \& Biological Psychiatry 18, 1307-1321.

Orozco, S., Ehlers, C.L., 1998. Gender differences in electrophysiological responses to facial stimuli. Biological Psychiatry 44, 281-289.

Orozco, S., Wall, T.L., Ehlers, C.L., 1999. Influence of alcohol on electrophysiological responses to facial stimuli. Alcohol $18,11-16$.

Polich, J., Bloom, F.E., 1987. P3 from normals and adult children of alcoholics. Alcohol 4, 301-305.

Polich, J., Bloom, F.E., 1988. Event-related brain potentials in individuals at high and low risk for developing alcoholism: failure to replicate. Alcoholism: Clinical and Experimental Research 12, 368-373.

Polich, J., Pollock, V.E., Bloom, F.E., 1994. Meta-analysis of P3 amplitude from males at risk for alcoholism. Psychological Bulletin 115, 55-73.

Porjesz, B., Begleiter, H., 1990. Event-related potentials in individuals at risk for alcoholism. Alcohol 7, 465-469.
Porjesz, B., Begleiter, H., 1998. Genetic basis of event-related potentials and their relationship to alcoholism and alcohol use. Journal of Clinical Neurophysiology 15, 44-57.

Ramachandran, G., Porjesz, B., Begleiter, H., Litke, A., 1996. A simple auditory oddball task in young adult males at high risk for alcoholism. Alcoholism: Clinical and Experimental Research 20, 9-15.

Ramsey, S.E., Finn, P.R., 1997. P300 from men with a family history of alcoholism under different incentive conditions. Journal of Studies on Alcohol 58, 606-616.

Robin, R.W., Long, J.C., Rasmussen, J.K., Albaugh, B., Goldman, D., 1998. Relationship of binge drinking to alcohol dependence, other psychiatric disorders, and behavioral problems in an American Indian Tribe. Alcoholism: Clinical and Experimental Research 22, 518-523.

Roschmann, R., Wittling, W., 1992. Topographical brain mapping of emotion-related hemisphere asymmetries. International Journal of Neuroscience 63, 5-16.

Sangal, R.B., Sangal, J.M., 1996. Topography of auditory and visual P300 in normal children. Clinical Electroencephalography 21 (1), 46-51.

Sangal, R.B., Sangal, J.M., Belisle, C., 1998. P300 latency and age: a quadratic regression explains their relationship from age 5-85. Clinical Electroencephalography 29, 1-6.

Spicer, P., 1997. Toward a (dys)functional anthropology of drinking: ambivalence and the American Indian experience with alcohol. Medical Anthropology Quarterly 11, 306-323.

Spicer, P., 1998. Narrativity and the representation of experience in American Indian discourses about drinking. Culture, Medicine and Society 22, 139-169.

Steinhauer, S.R., Hill, S.Y., 1993. Auditory event-related potentials in alcoholics and their first-degree relatives. Journal of Studies on Alcohol 54, 408-421.

US Indian Health Service, 1982. Analysis of Fiscal Year 1981 Indian Health Service and U.S. Hospital Discharge Rates by Age and Primary Diagnosis. US Government Printing Office, Washington, DC.

Vanderploeg, R.D., Brown, W.S., Marsh, J.T., 1987. Judgments of emotion in words and faces: ERP correlates. International Journal of Psychophysiology 5, 193-205.

Van der Stelt, O., Geesken, R., Gunning, W.B., Snel, J., Kok, A., 1998. P3 scalp topography to target and novel visual stimuli in children of alcoholics. Alcohol 15, 119-136.

Wall, T.L., Ehlers, C.L., 1995. Acute effects of alcohol on P3 in Asians with different ALDH2 genotypes. Alcoholism: Clinical and Experimental Research 19, 617-622.

Wall, T.L., Garcia-Andrade, C., Thomasson, H.R., Cole, M., Ehlers, C.L., 1996. Alcohol elimination in Native American Mission Indians: An investigation of inter individual variation. Alcoholism: Clinical and Experimental Research 20, 1159-1164.

Wall, T.L., Garcia-Andrade, C., Thomasson, H.R., Ehlers, C.L., 1997. Alcohol dehydrogenase polymorphisms in Native Americans: Identification of the $\mathrm{ADH}_{2} * 3$ allele. Alcohol and Alcoholism 32, 129-131. 
Wall, T.L., Garcia-Andrade, C., Wong, V., Lau, P., Ehlers, C.L., 2000. Parental history of alcoholism and problem behaviors in Native American children. Alcoholism: Clinical and Experimental Research 24, 30-34.

Whipple, S., Parker, E., Noble, E., 1988. An atypical neurocog- nitive profile in alcoholic fathers and their sons. Journal of Studies on Alcohol 49, 240-244.

Young, T.J., 1991. Native American drinking: a neglected subject of study and research. Journal of Drug Education $21,65-72$. 